\title{
The Port System Metropolitan for City of Reggio Calabria
}

\author{
Raffaele Scrivo ${ }^{1, a}$ \\ ${ }^{1}$ Mediterranea University of Reggio Calabria - PAU - Department of Heritage, Architecture, Urban \\ Planning, Via Salita Melissari - 89124, Reggio di Calabria, Italy \\ araffaele.scrivo@unirc.it
}

Keywords: Marina, Port System Metropolitan, Development of the Area, Integrated Planning.

\begin{abstract}
Reggio Calabria becomes a metropolitan city with the law $\mathrm{n}^{\circ} 135$ August 7, 2012. The new local authority should not only be an automatic replacement of the province, but it has to start processes of sustainable development of the territory, through processes and integrated programs in services and infrastructure. The expectations are starting innovative governance, streamlined and efficient and to provide services and infrastructure to the area of high rank through strategic planning and shared. The theme of port system take on strategic importance in a context that is a candidate to be a reference point in the Mediterranean. The port, many times, has been interpreted as a driving force of development, but it has often been conceived only in its technical-functional elements. The experiences and analyses of efficient port reality show that, for the construction of a port system, an integrated approach is necessary [3]: it should considers social, economic and financial aspects.
\end{abstract}

\section{Introduction}

The European Union imagines [1], that the territorial level of the metropolitan city is the most able to address the challenges in terms of economic competitiveness and social development of the territories. Metropolitan city has not a established definition, but the intentions of the new local authority are to give birth to innovative governance, slender and efficient and to provide services and infrastructure to the area of high rank through strategic planning and shared. The metropolitan city must be able to identify resources and time to trigger processes of economic revitalization and increase the level of competitiveness of its territory compared to the best European experiences. An objective of the metropolitan city of Reggio Calabria is to become a reference point in the Mediterranean Area; a key objective to reach one of the provided programs is the creation of a port system [5] with a touristic vocation.

In this paper i explain a methodology for the development of tourist metropolitan ports, analyzing the status quo and through an integrated and multidisciplinary approach.

\section{The concept of port}

The port was often conceived as a driving force for the development of the territory (such as a new highway to grow and bring development). The port, airport or highway infrastructures are only necessary, but they don't work directly on the production system, they are created to meet human social and economic needs of an area. The territory, the city, now in their metropolitan meaning, and infrastructures, are closely related to each other; variables and social, cultural and economic conditions characterize territories, influence the size, the type, the image of the infrastructures. Imagine an infrastructure for a place can not do without careful knowledge of the same in which the term is used in order to understand what are the interactions, the positive or negative effects, its real utility and the ability to help in the process development.

Ports are special infrastructure; they may interact positively or negatively with the territory, complete it, being completely alien or even destroy it (e.g. erosion of the coastline, urban decay)

The ports can be grouped according to their location (inner harbor, outer harbor, river port, etc.). According to the shape of the pier (port channel, jetties converged harbor basin, etc.), based on the specific activities (military ports, harbors commercial, industrial ports, the ports of speed, fishing 
ports, marinas and ports internodes). The Italian Law n ${ }^{\circ} 84$ of 1994, establishes the Port Authorities and distinguishes the ports into two categories and three subclasses (Table 1). The law provides that the state builds and maintains the ports of the the first category and first-class of the second category, while regions and municipalities have the responsibility of the other ports.

Table 1. Breakdown of Italian ports according to the Law $\mathrm{N}^{\circ} 84$ of $28 / 01 / 1994^{1}$

\begin{tabular}{|c|c|l|l|}
\hline CATEGORY & CLASS & \multicolumn{1}{|c|}{ FEATURES } & TYPES \\
\hline I & & Specific ports or port areas, for military defense and state security. & Military \\
\hline II & I & Specific ports or port areas of economic importance internationally. & \multirow{2}{*}{ Commercial, industrial, fishing, tourism and speed. } \\
\cline { 1 - 3 } II & II & Specific ports or port areas of national economic importance. & \\
\cline { 1 - 3 } II & III & Specific ports or port areas, regional or interregional economic importance. & \\
\hline
\end{tabular}

The same marina could itself be divided into two broad categories [2], which differ depending on usage and the type of vessel to which they address:

- ports of residence or home port, facilities where boaters take the boat moored typically located in close proximity to town where there is a substantial demand for berths and with people with a good spending capacity;

- ports of transit facilities where boaters transiting short periods during a navigation path that possess essential service limited to supplies (fuel, water, electricity) and technical assistance (depannage), and medical tourism. This category is essential to the safety and comfort of the berth, as the amenity of the site and of the port aesthetics since users normally are sleeping on a boat and spending hours and days on the docks;

These latest can also be divided into three types [2]:

- the "parking of boats," structures where the formula is based on offering competitive services aimed primarily to the needs of mooring (parking) of the vessels of resident and nonresident boat owners and the value of the offer is based on whether access to the sea for boaters;

- the "squares on the sea", which in addition to the landing craft, they represent the "experiential platform" for entertainment, socializing and enjoyment of leisure boaters, residents and tourists not boaters. In these cases there is a strong cultural relationship with the rest of the city, which identify a place of supply of services and themed experiences on the relationship with the sea (accommodation, food, trade, cultural events, recreational events, etc.).

- "villages of boating," port systems dedicated to boaters and lovers of the sea, typically inserted in environmental contexts and territorial highly contextualized and unique, suitable for use exclusive and elitist forms of financial offers.

This type, so varied, shows how it can be complex to define a model of port system and adequately address the project proposals.

\section{The status quo}

Studies show [3] that the best reality ports are located in highly consolidated area from the point of view of tourism. The port with resident function ${ }^{2}$, get the best financial performance in places behind a considerable catchment (Fig.1) area and where there is a strong tourist attraction due to an already consolidated ${ }^{3}$ context.

\footnotetext{
1 The membership of a port to Category II and its class is through a decree of the Ministry of Transport and Navigation feel the Port Authority or the Maritime taking into account:

- extent of global traffic and their components;

- operational capacity of the airports resulting from the functional characteristics and situations of safety with respect to environmental risks and impacts of equipment, both for the embarkation and disembarkation of passengers and for loading, unloading, maintenance and storage of goods and equipment and services suitable for refueling, maintenance, repair and assistance in kind of ships and boats.

- the level and efficiency of the services link with the hinterland.

2 Lotti Harbor(Liguria). Notice how the flow of Liguria represent the landlocked for the Piedmont Region and partly because of the Lombardy Region.

3 Harbor Cervo (Sardegna).
} 


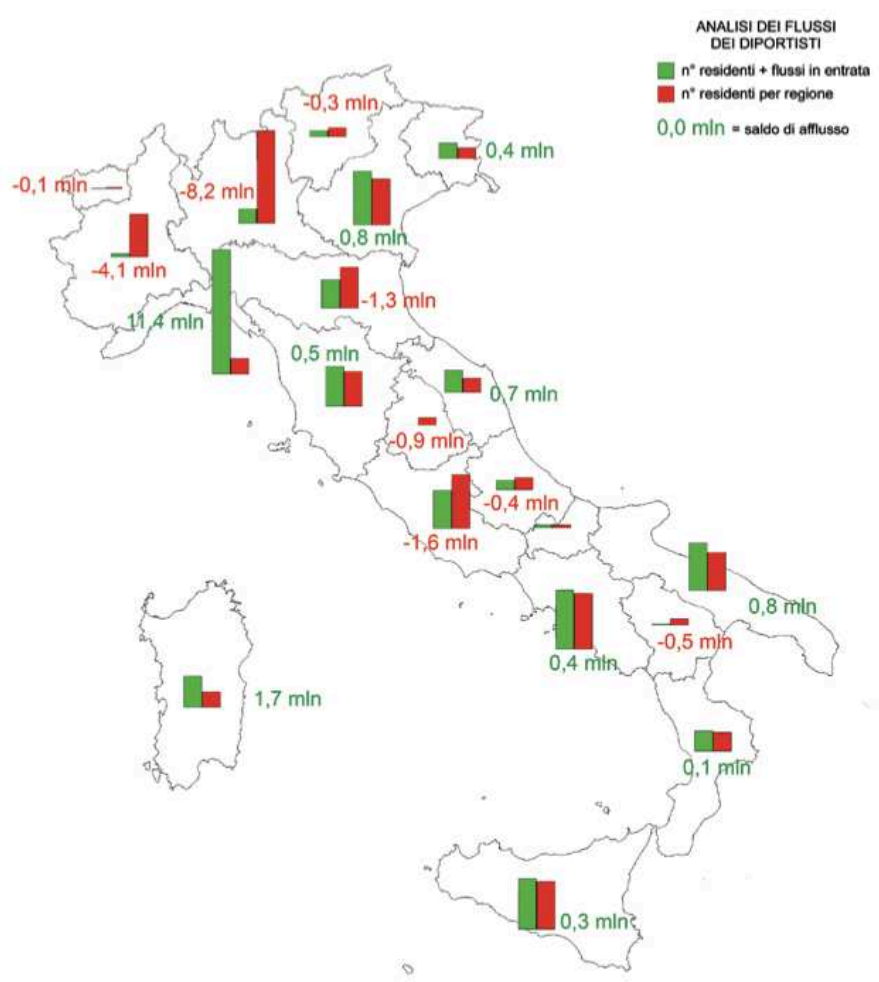

Fig. 1 Analysis of the flow of boaters [4]

The application of yachting in Calabria [4] is concentrated mainly in the high season, especially for transit traffic to the Aeolian Islands and Sicily and it does not reach levels of particular entity, there is a foreign demand that seems to cater mostly on the Ionian coast, and particularly accentuated in low season (April, June, September, November: mainly they are foreign tourists to travelling to Greece), with the result that each individual port does not reach considerable levels of financial performance, with rare exceptions ${ }^{4}$.

In the province of Reggio Calabria there are different types of ports (see Table 2). There are the port of Gioia Tauro (commercial port) and the port of Villa San Giovanni (we could call them internode) and other 6 port for wich there is not a specific and distinction of operation and activity, since they receive both functions of plasure craft, with general service, and fishing activity.

Table 2. Existing ports in Province of Reggio Calabria. [5] * Porto affected by the works. ** Not for use coverup.

\begin{tabular}{|c|c|c|c|c|c|}
\hline Porti & Provincia & Tipologia & Litorale & Posti barca & Funzioni Strategiche \\
\hline Reggio Calabria & $\mathrm{RC}$ & Docks in marina / Commercial Harbor / Passenger Service & Tirrenico & 50 & Cruise port \\
\hline Roccella ionica & $\mathrm{RC}$ & Marina/ fishing port & Ionico & 447 & \\
\hline Scilla & $\mathrm{RC}$ & Marina/ fishing port & Tirrenico & 100 & \\
\hline Gioia tauro & $\mathrm{RC}$ & Harbor industrial & Tirrenico & 120 & \\
\hline Palmi ..... & $\mathrm{RC}$ & Marina/ fishing port & Tirrenico & 200. & \\
\hline Bagnara & $\mathrm{RC}$ & Marina/ fishing port & Tirrenico & 60 & \\
\hline Villa S. Giovanni & $\mathrm{RC}$ & Commercial port quay/Passenger Service & Tirrenico & non disponibile* & \\
\hline Saline Joniche & $\mathrm{RC}$ & Commercial port quay & Ionico & non disponibile** & \\
\hline Totale & & & & 977 & \\
\hline
\end{tabular}

The Calabria Region, in its Masterplan for the port system is expected to increase the allocation of berths at least triple (see Table 3 and Fig.2), compared with an availability of approximately 5.300 berths, making an offer of at least 15.000 berths, providing the strategic work of the cruise for pole some ports, aiming to specialize the offer to the yachting and boating system. Only in the 
province of Reggio Calabria ${ }^{5}$, it involves the construction of an additional 6 new ports for a budget of around 2.000 berths, which added to the already existing around 1.000 would reach a total of about 3.000 berths. In this way, the only province of Reggio Calabria would have a port approximately every $16 \mathrm{~km}$ of coastline, and almost 14 berths each $\mathrm{km}$ of coastline (making a comparison with only some regions are respectively Tuscany 10,3 and 38,9, Lazio 10 and 31; Campania 10,4 and 23,6). ${ }^{6}$

Table 3. Harbours in the project for the Region Calabria [5]

\begin{tabular}{|l|l|l|l|r|}
\hline Porti & Provincia & Tipologia & Litorale & $\begin{array}{l}\text { Posti barca } \\
\text { previsti }\end{array}$ \\
\hline Scilla & $R C$ & Porto turistico & Tirrenico & 360 \\
\hline Catona & $\mathrm{RC}$ & Porto turistico & Tirrenico & 450 \\
\hline Pellaro & $\mathrm{RC}$ & Porto turistico & Ionico & 300 \\
\hline Palizzi & $\mathrm{RC}$ & Porto turistico & Ionico & 200 \\
\hline Bovalino & $\mathrm{RC}$ & Porto turistico & Ionico & 300 \\
\hline Locri & $\mathrm{RC}$ & Porto turistico & Tirrenico & 450 \\
\hline Totale & & & & 2060 \\
\hline
\end{tabular}

\section{The territory}

The Metropolitan City of Reggio Calabria has many potentialities in terms of attractiveness and tourist flows, depending on the presence of a significant historical and cultural heritage and environmental assets that, still appears undervalued and insufficient to provide substantial offer to the tourist. Recent studies ${ }^{7}$, in fact, showed that the main reason for the yachting and nautical tourism lies in the desire to live the sea and not so much the land behind him. This supports the hypothesis that it is not so much the marina which generates a question but it is the vocation of the context, consolidating, which may require his presence [3,4]. A search on Italian tourist ports [3] shows that the ports of success are those in tourist areas and known backed by a considerable catchment area and in contexts where there is a good availability of user spending to chattels defined "luxury".

Therefore the importance of the tourist attraction of the area is a key element to justify the construction of the marina it is somewhat controversial, there is a clear and direct relationship between the development of yachting and nautical tourism transit on the presence on the ground factors of tourist attraction $[2,3,4]$. The tourist port is however a node, it is part of a complex value chain [3] of the tourism industry and transport terms, but it is not economically sustainable by definition. Sailing tourism, evolves on scales of changing needs that go beyond the simple product service, to achieve articulated product systems such as receptivity, the playful and culture. In addition, the operation of a port, beside being related in the way to integrate with the region and its tourist and cultural resources, must enter in the system with the rest of the existing port facilities, or in order to have a common management or strategy shared, so as to constitute a network which offers various types of complementary service between them.

In this way it is possible to define a metropolitan port system, where infrastructure is interconnected with each other and with the land in pursuit of virtuous actions for economic growth and development [7].

5 For a complete description please refer to http://www.urbanistica.regione.calabria.it/allegati/attivita/masterplan/masterplan.pdf 
The marina badly needs to be contextualized and characterized with respect to the territory in which it is part, with respect to the needs of the user, and falls within a logical system [2], where the best port for the Metropolitan interacts with the tourist offer metropolitan, structured and in turn connected to the system of mobility in general. This would make it possible to start the so-called tourism, "traveling", formed by boaters who do it with their own boat cruising in the medium and long-range stopping at some of the ports they encounter along the way. The inclusion of the port as part of an extensive network of other functionally related infrastructure seems to be an important requirement for assessing the attractiveness and competitiveness of the port and of the pleasure boating, it allows you to start a semi-permanent navigation between the different locations.

Those findings come from observations of national experiences but especially international, who conceived the marina is part of a district or touristic system has already begun, which sees the ports as the crowning of the same system, integrating it in and completing the offer, and not infrastructure as an incentive for future development.

The sustainability of the marina is a problem especially an economic problem.

Therefore, to develop a system of port with metropolitan character, it is necessary to proceed by stages between them inserted into perspective preliminary design of the integrated system, taking then:

- the existence of a significant user base;

- sites strategically located with respect to the offer local cultural and tourist hinterland, in order to meet the needs of moorings stable expressed in terms of the number and size of vessels and to serve as a base for excursions and cruises;

- ability to create a tourist circuit-nautical or based on other cruise ports, placed at a distance of a few hours sailing from (15-30 miles) in places that have the character of the destination or the quality to become such, these ports are configured as transit and/or ports of refuge equipped therefore with essential services and localized contexts with sufficient tourist attraction.

\section{A scientific methodology for the port system metropolitan}

The steps that may pose a methodology to define a port system metropolitan are identified in:

1. An analysis of direct permanent demand of user; this defines the catchment area who permanently uses the port for the entire period of the year. At this stage it might be useful to identify some of the indicators that can represent the spending power of visitors to this area.

2. An analysis demand user in transit, it is essential to analyze the routes of boaters regarding the proximity to places of tourist interest and the goal to be achieved which can be closely linked to the pleasure of experiencing the sea.

3. Context analysis, which highlights the relationships with any historical and cultural attractors as the same are available, then analyzing the connections with the mobility infrastructure present; even if users are mainly migratory reach the port by car, users of other Italian regions and foreign countries would use the port with a starting point to reach the more distant (e.g. the ports of Tropea and Vibo Marina are being used by users from Lazio and Campania, from foreigners who leave throughout the year the boat in storage and then use it to reach the Aeolian Islands in the summer). It is therefore necessary to consider the time and cost of distance indicators, to assess the sustainability from the point of view of the user and also in optical alternatives to other destinations potentially competing port.

In these three steps you define the marketplace, that is, those who use the port, assessed according to the distance from the infrastructure, the availability of shopping and the prospects for development.

4. Financial analysis, a tourist port is generally managed by a private company it has reason to do manage it only with substantial profitability. Therefore already in the prodromal phase to the design, as are the pre-feasibility studies [6], verify, through appropriate performance indicators, net present value (NPV) and internal rate of return (IRR), profitability of private management. This 
would make it possible to already be defined in the form of public-private partnerships more suited to a sustainable management [8].

Obviously in a metropolitan system ports for a touristic offer, you can not leave out the participation of institutional actors such as:

- the authorities responsible choices related to scheduling, planning and control and defense of the territory (Region, City Metro, municipalities, port authorities);

- population, cultural associations, sports, category (hoteliers, traders ... etc..).

\section{Conclusion}

Then, to define a metropolitan tourist port system is not possible without an integrated approach that takes into account the heterogeneous aspects of the territory, the different users' needs and falls within the broader program of tourist development of the entire metropolitan area where every aspect is "measured" according to the principles of sustainable development. This "measurement" is needed to happen anyway in the process of programming choices, through a process of appraisal that takes into account economic and financial aspects.

\section{References}

[1] Information on: http://ec.europa.eu/regional_policy/sources/docgener/studies/pdf/citiesof tomorrow/citiesoftomorrow_final.pdf

[2] E. Colombo, P. Viola: Porti turistici: approccio multidisciplinare per una strategia progettuale integrata, Dario Flaccovio, Palermo (2010)

[3] F. Quagli (a cura di): Analisi gestionale dei porti turistici nella nautica da diporto, Franco Angeli, Milano (2008)

[4] Rapporto sul turismo nautico n. 2 anno (2010)

[5] Information on: http://www.urbanistica.regione.calabria.it/allegati/attivita/masterplan/ masterplan.pdf.

[6] R. Mascarucci (a cura di): Fattibilità e progetto - Territorio economia e diritto nella valutazione preventiva degli investimenti pubblici, Franco Angeli, Milano, 2011

[7] F. Calabrò, L. Della Spina: The cultural and environmental resources for sustainable development of rural areas in economically disadvantaged contexts. Economic-appraisals issues of a model of management for the valorisation of public assets. In: 3rd International Conference on Energy, Environment and Sustainable Development (ICEESD 2013). Advanced Materials Research Vols. 869-870 (2014) pp 43-48 (C) (2014) Trans Tech Publications, Switzerland doi:10.4028/www.scientific.net/AMR.869-870.43, (2014)

[8] F. Calabrò, L. Della Spina: The public-private partnerships in buildings regeneration: a model appraisal of the benefits and for land value capture. In: 5nd International Conference on KKU Conferenza Internazionale 2014 (KKU-IENC 2014). ADVANCED MATERIALS RESEARCH. In press. 